\title{
Sub-national disparities in accessing anti- malarial drug treatment in eastern Indonesia
}

Mara Ipa ${ }^{1 *}$ DD, Agung Dwi Laksono ${ }^{2}$, Endang Puji Astuti ${ }^{1}$, Heni Prasetyowati ${ }^{1}$, Firda Yanuar Pradani ${ }^{1}$, Joni Hendri ${ }^{1}$, Andri Ruliansyah', Henry Surendra ${ }^{3,4}$ and lqbal R. F. Elyazar ${ }^{3}$

\begin{abstract}
Background: Poor access to health care providers was among the contributing factors to less prompt and ineffective malaria treatment. This limitation could cause severe diseases in remote areas. This study examined the sub-national disparities and predictors in accessing anti-malarial drug treatment among adults in Eastern Indonesia.

Methods: The study analyzed a subset of the 2018 National Basic Health Survey conducted in all 34 provinces in Indonesia. We extracted socio-demographic data of 4655 adult respondents diagnosed with malaria in the past 12 months in five provinces in Eastern Indonesia. The association between socio-demographic factors and the access to anti-malarial drug treatment was assessed using logistic regression.

Results: Over $20 \%$ of respondents diagnosed with malaria within last 12 months admitted that they did not receive anti-malarial drug treatment (range 12-29.9\%). The proportion of untreated cases was 12.0\% in East Nusa Tenggara, 29.9\% in Maluku, 23.1\% in North Maluku, 12.7\% in West Papua, and 15.6\% in Papua. The likelihood of receiving antimalarial drug treatment was statistically lower in Maluku (adjusted $\mathrm{OR}=0.258 ; 95 \% \mathrm{Cl} 0.161-0.143$ ) and North Maluku (adjusted OR $=0.473 ; 95 \% \mathrm{Cl} 0.266-0.840$ ) than those in Eastern Nusa Tenggara (reference). Urban respondents were less likely to receive malaria treatment than rural (adjusted $\mathrm{OR}=0.545 ; 95 \% \mathrm{Cl} 0.431-0.689$ ).

Conclusions: This study found that there were sub-national disparities in accessing anti-malarial drug treatment in Eastern Indonesia, with a high proportion of untreated malaria cases across the areas. Findings from this study could be used as baseline information to improve access to anti-malarial drug treatment and better target malaria intervention in Eastern Indonesia.
\end{abstract}

Keywords: Sub-national disparities, Anti-malarial drug, Eastern Indonesia, The 2018 Indonesia basic health survey, Public health

\footnotetext{
* Correspondence: tiarmara@gmail.com

${ }^{1}$ Pangandaran Unit for Health Research and Development, National Institute

of Health Research and Development, Ministry of Health of Indonesia,

Pangandaran, West Java, Indonesia

Full list of author information is available at the end of the article
}

(c) The Author(s). 2021 Open Access This article is licensed under a Creative Commons Attribution 4.0 International License, which permits use, sharing, adaptation, distribution and reproduction in any medium or format, as long as you give appropriate credit to the original author(s) and the source, provide a link to the Creative Commons licence, and indicate if changes were made. The images or other third party material in this article are included in the article's Creative Commons licence, unless indicated otherwise in a credit line to the material. If material is not included in the article's Creative Commons licence and your intended use is not permitted by statutory regulation or exceeds the permitted use, you will need to obtain permission directly from the copyright holder. To view a copy of this licence, visit http://creativecommons.org/licenses/by/4.0/ The Creative Commons Public Domain Dedication waiver (http://creativecommons.org/publicdomain/zero/1.0/) applies to the data made available in this article, unless otherwise stated in a credit line to the data. 


\section{Background}

Malaria elimination strategy requires strong early diagnosis capacity and effective prompt treatment [1]. However, delivering prompt treatment can be particularly challenging in rural areas with poor access to anti-malarial drug treatment [2]. As one of Southeast Asia's countries with the highest malaria burden and varied epidemiological and entomological landscape [3, 4], Indonesia is complicated by high contribution of malaria from rural settings in Eastern provinces. Although most districts in western and central Indonesia have been certified malaria-free in 2020, five provinces in Eastern Indonesia i.e., Papua, West Papua, Maluku, North Maluku, and East Nusa Tenggara contributed to over $60 \%$ of total malaria cases in Indonesia [5]. Forest ecosystem and mobility factors (mobile and migrant population) added the complexity of malaria problem in these settings [6].

Indonesia is aiming to achieve malaria elimination by 2030 [7]. In order to improve malaria treatment access, the Indonesian government has implemented the early detection and administration of anti-malarial drugs by empowering local malaria cadres, especially in areas with limited access to health service facilities, lack of health staff, and medical supplies [8]. However, while the majority of provinces $(25 / 34)$ in the western and central regions of Indonesia has achieved ACT coverage above $90 \%$, the Eastern region has not achieved the targeted coverage, particularly in Maluku $(74,7 \%)$ and ENT $(80,1 \%)$ [9].

Previous studies documented varied factors that affect health services accessibility, malaria awareness and attitudes, and socioeconomic characteristics [10-15]. Distance to health facility, limited transportation to reach rural and remote areas, self-medication, low treatment rate, limited availability to health staff and medical supplies, are responsible to the malaria problems [16-18]. National Malaria Information System reported provinces in Eastern Indonesia had lower target coverage of malaria treatment than in Western Indonesia. This study assessed sub-national disparities and predictors in accessing anti-malarial drug treatment in five provinces in Eastern Indonesia.

\section{Methods}

\section{Study sites}

The study limited analysis to five provinces in Eastern Indonesia that had a high malaria annual parasite incidence (API) (Maluku, API $=1,16 \%$; North Maluku 0,39\%; East Nusa Tenggara 3,42\%o; West Papua 8,49\%; and Papua 52,99\%o) $[5,9]$. These areas were chosen as representative of high endemic areas of Indonesia, which contributed to $91.68 \%(n=165,217)$ of Indonesia's national malaria cases in 2017 (2018 Indonesia Health Profile).
The province of Maluku consists of 11 districts $\left(54,185 \mathrm{~km}^{2}\right)$, with a population of 1.5 million people [19]. North Maluku consists of 10 districts $\left(31,982 \mathrm{~km}^{2}\right)$, with a population of around $1,038,087$ people [20]. The ENT consists of 22 districts $\left(47,931 \mathrm{~km}^{2}\right)$, with approximately 4.6 million inhabitants [21]. West Papua consists of 13 districts $\left(99,671 \mathrm{Km}^{2}\right)$, populated by over 800,000 people [22]. Papua has 29 districts $\left(316,553 \mathrm{~km}^{2}\right)$, with a population of 2.8 million people [23].

\section{Study design and data collection}

This study was a secondary analysis of the 2018 Indonesia Basic Health Survey conducted by the National Institute of Health Research and Development (NIHRD), Ministry of Health of Indonesia. The survey was a community-based cross-sectional survey conducted in 34 provinces, from April to May 2018. This survey aimed to assess public health indicators key for policymaking at national, provincial, and district-level. The present study employed a subset of the 2018 Indonesia Basic Health Survey data. Sample were collected using a systematic random sampling model and a probability proportional to size approach by stratified multi-stage sampling. Data collection was carried out by around 10,000 trained enumerators with a minimum qualification of health graduate diploma. The enumerators were trained on how to obtain written informed consent, conducting interview, and completing questionnaires and other data collection forms. During data collection, the enumerators were supervised by at least one designated field coordinator employed at each district. These enumerators visited selected households accompanied by local health authorities and village leaders. The study followed informed consent protocols, and the enumerators collected information using standardized questionnaires via face-to-face interviews. The questionnaire consisted of several sections, including the household level section and individual-level section. Malaria was one of the infectious diseases included in the questionnaire.

In particular, the 2018 Indonesia Basic Health Survey surveyed 295,720 households with 1,091,528 household members in 34 provinces; for this analysis, a subset of data from five selected provinces were analyzed. The analysis was restricted to samples aged $\geq 15$ years for this study ( $n=4665)$; we chose this as it corresponds to the age group within the age range defined as an adolescent in Indonesia [24].

\section{Data source}

The data source for this study was the 2018 Indonesia Basic Health Survey conducted by the National Institute of Health Research and Development (NIHRD), Ministry of Health of Indonesia. We restricted our analysis among $\geq 15$ 
years old individuals $(n=4665)$ in five provinces: Papua $(n=2876)$, West Papua $(n=558)$, Maluku $(n=147)$, North Maluku $(n=121)$ and East Nusa Tenggara $(n=963)$.

\section{Variables}

The study's variables were measured by interview using the standardized questionnaire used in the Indonesia Basic Health Survey series, published in reports and scientific articles $[5,25]$. In this analysis, the outcome variable was anti-malarial drug treatment. The variable is coded as " 1 " if a household member received an anti-malarial drug, i.e., he/she has been given the anti-malarial medication (ACT 3 days + Primaquin 1 day or taking anti-malarial drug ACT 3 days + Primaquin 14 days) after diagnosed in the past 12 months by local health care providers/physicians as having positive laboratory-confirmed malaria before the survey; and " 0 " if he/she reported otherwise. The answer to this question was binary: code 1 (Yes) and code 0 (No). Malaria has typically been confirmed in health facilities using Rapid Diagnostic Tests (RDTs) and microscopy. For this study, the interviewer carried out no screening tests. The study construct variables based on respondents' recall of whether they have been given anti-malarial drugs after laboratory diagnosed malaria in the past 12 months.

The explanatory variables were age (grouped into two categories: 15-24, and more than 24 years), gender (male/female), place of residence (urban/rural), marital status (single/married), education level (did not complete primary education, completed primary, secondary or tertiary education). Occupation was categorized into three: (1) unemployed, including students; (2) farmer, including farmer, fisherman; and (3) non-farmer, including civil employee, private employee, entrepreneur, labor/driver/housemaid. Wealth status (poorest, poorer, middle, richer, and richest), access to health insurance (Yes/No) and transportation cost ( $\leq$ Rp. 15,000/ > Rp. 15,000).

\section{Statistical analysis}

At the initial stage of the analysis, the study performed a bivariate analysis using the chi-square test to see differences in accessing anti-malarial drug treatment and respondents' sociodemographic between provinces. In the next stage, the study tests all variables using a collinearity test to ensure no symptoms of a strong relationship between the independent variables. At the final stage, the study employed a logistic regression because of the nature of the dependent variable. The author performs all statistical analyzes by SPSS 22 software. The study generated a map of the geographical distribution of antimalarial drug treatment distribution in ArcGIS 10.5 (ESRI Inc., Redlands, CA, USA). The author obtained the shapefile of administrative boundary polygons from the Bureau of Statistics of Indonesia) (http://www. silastik.bps.go.id).

\section{Results}

Figure 1 presents the spatial distribution of anti-malarial drug treatment in eastern Indonesia, including Maluku, North Maluku, East Nusa Tenggara (ENT), West Papua, and Papua Province. The proportion of respondents who did not receive anti-malarial treatment was $12.0 \%$ in East Nusa Tenggara, 29.9\% in Maluku, 23.1\% in North Maluku, $12.7 \%$ in West Papua, and $15.6 \%$ in Papua (Table 1).

\section{Characteristic of respondents}

Table 1 provides the socio-demographic characteristics of surveyed respondents. Most of respondents lived in rural areas and also received anti-malarial drugs. Respondents in the North Maluku had slightly older than respondents in the other areas. Malaria was more prevalent in males at all provinces, except in the East Nusa Tenggara. Higher proportion of respondents was observed with primary education background. Patients as farmers and un-employed patients contributed about a half of total respondents. Over $50 \%$ of respondents reported poor wealth status. Most of respondents had health insurance. High proportion of respondents mentioned the they spent transportation costs to nearest health facility less than 15,000 IDR (amount 1 \$ US).

\section{Factors associated with anti-malarial treatment}

Table 2 shows the final logistic regression model assessing factors associated with access to anti-malarial drug treatment in Eastern Indonesia. The model shows that malaria patients in Maluku and North Maluku were less likely to have anti-malarial drug treatment than those patients in East Nusa Tenggara (ENT), adjusted OR (aOR) 0.258 (95\% CI 0.161-0.413), and 0.473 (95\% CI 1.266-0.840), respectively. Moreover, there was no significant difference in proportion of patients who have anti-malarial drug treatment in West Papua (aOR 0.951; 95\% CI 0.648-1.396), and Papua (aOR 0.894; 95\% CI 0.682-1.172), compared to that in ENT.

The multivariable analysis also found that place of residence, occupation, and wealth status were associated with anti-malarial drug treatment in Eastern Indonesia. The odd of having anti-malarial drug treatment was lower for malaria patients living in urban areas compared to those living in rural (aOR 0.545; 95\% CI 0.4310.689). Patients whose occupation as farmers were more likely to have anti-malarial drug treatment than those who were unemployed (OR 1.381; 95\% CI 1.003-1.903). The poorer and richer patients were less likely to have anti-malarial drug treatment than the poorest, aOR 0.614 (95\% CI $0.451-0.836$ ), and 0.630 (95\% CI $0.463-$ 


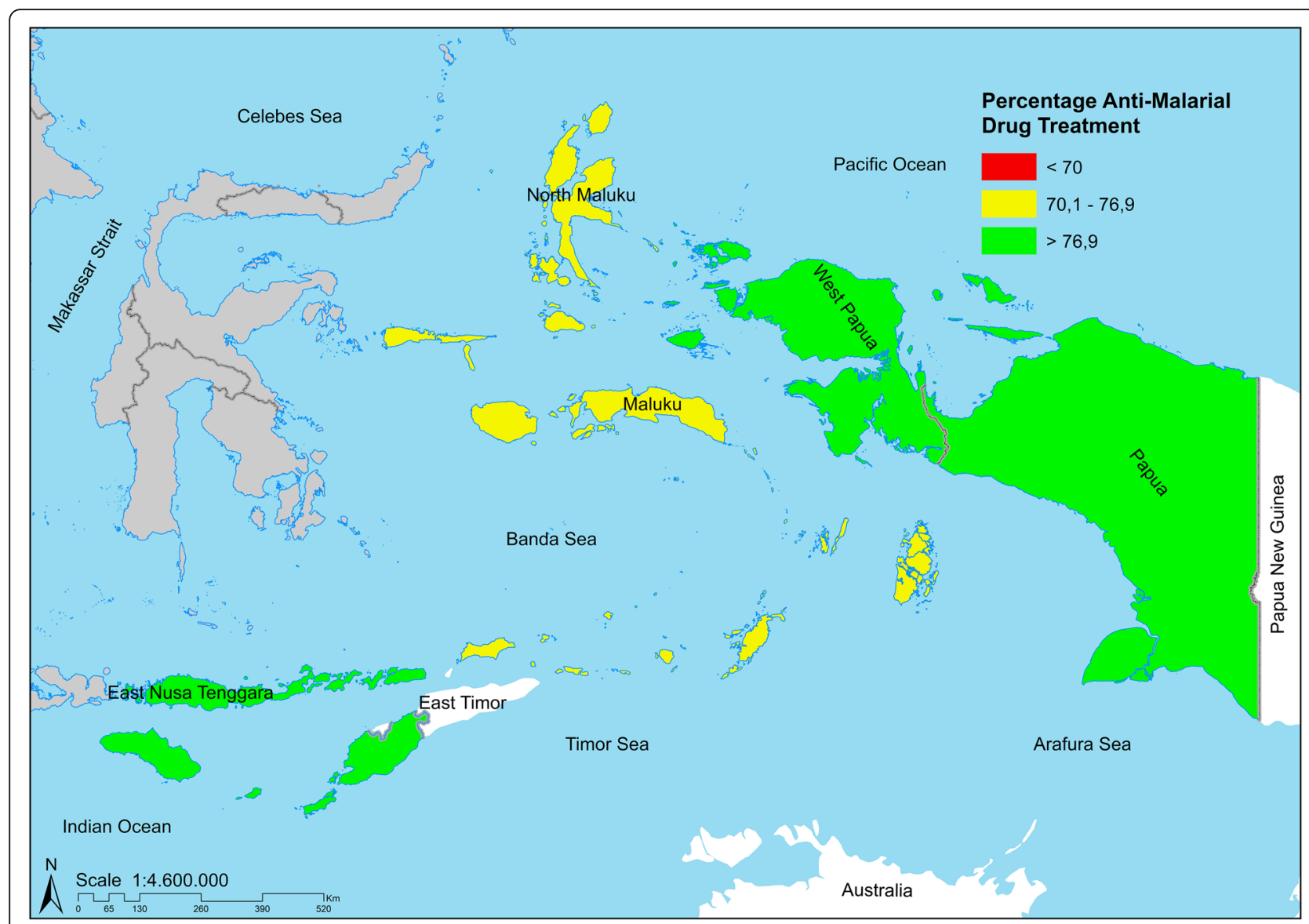

Fig. 1 The geographic distribution of anti-malarial drug treatment distribution among adults $\geq 15$ years old in eastern Indonesia (see Table 1 for values). The map depicted in the image belongs to the author. The map is generated using ArcGIS 10.5 (ESRI Inc., Redlands, CA, USA). The author obtained the shapefile of administrative boundary polygons from the Bureau of Statistics of Indonesia) (http://www.silastik.bps.go.id)

0.857), respectively. There was no significant association between age, gender, marital status, education level, health insurance, and transport cost to health facility, with access to anti-malarial drug treatment in Eastern Indonesia.

\section{Discussion}

This study described the analysis of subset data from a nationwide community-based, cross-sectional survey conducted in Indonesia in 2019 (the 2018 Indonesia Basic Health Survey). The study revealed geographical variations and factors associated with access to antimalarial drug treatment among malaria patients living in high endemic settings in the Eastern Indonesia. The odd of having anti-malarial drug treatment was associated with residence, occupation, and wealth status. There were no associations between age, gender, marital status, education level, health insurance, and transportation cost to health facility, with access to anti-malarial drug treatment in the Eastern Indonesia.
Malaria patients in ENT, Papua, West Papua, were more likely to access anti-malarial drug treatment than those patients in Maluku and North Maluku. Interestingly, in these areas, there were three provinces with the higher proportions of patients without any formal education, and with poorest wealth status. Thus, the findings contrast with other previous research findings concluding that lower education and economic status were associated with lower access to anti-malarial drug treatment. This potentially reflects other factors could have more impact on increasing access to anti-malarial drug treatment but were not assessed in this study. For examples, disparities in mass malaria elimination campaign, the availability of the malarial drugs at the primary healthcare facilities level, and the potential role of research institutions and local non-government organizations [26-28].

This study also revealed that the odd of having antimalarial drug treatment was higher among farmers. A possible explanation for this is because farming work is often associated with higher exposure to malaria in many malaria-endemic areas in Indonesia due to doing 
Table 1 Descriptive statistic socio-demographic of the respondent in accessing anti-malarial drug treatment by the province in Eastern Indonesia $(n=4665)$

\begin{tabular}{|c|c|c|c|c|c|c|c|c|c|c|c|}
\hline \multirow[t]{3}{*}{ Characteristics } & \multicolumn{10}{|c|}{ Region/Province } & \multirow[t]{3}{*}{$P$} \\
\hline & \multicolumn{2}{|c|}{ East Nusa Tenggara } & \multicolumn{2}{|c|}{ Maluku } & \multicolumn{2}{|c|}{$\begin{array}{l}\text { North } \\
\text { Maluku }\end{array}$} & \multicolumn{2}{|c|}{ West Papua } & \multicolumn{2}{|c|}{ Papua } & \\
\hline & $\bar{n}$ & $\%$ & $\bar{n}$ & $\%$ & $\mathrm{n}$ & $\%$ & $\bar{n}$ & $\%$ & $\mathrm{n}$ & $\%$ & \\
\hline \multicolumn{12}{|l|}{ Malaria treatment } \\
\hline No & 116 & $12.0 \%$ & 44 & $29.9 \%$ & 28 & $23.1 \%$ & 71 & $12.7 \%$ & 448 & $15.6 \%$ & \multirow[t]{2}{*}{$<0.001$} \\
\hline Yes & 847 & $88.0 \%$ & 103 & $70.1 \%$ & 93 & $76.9 \%$ & 487 & $87.3 \%$ & 2428 & $84.4 \%$ & \\
\hline \multicolumn{12}{|l|}{ Place of residence } \\
\hline Urban & 128 & $13.3 \%$ & 45 & $30.6 \%$ & 29 & $24.0 \%$ & 185 & $33.2 \%$ & 857 & $29.8 \%$ & \multirow[t]{2}{*}{$<0.001$} \\
\hline Rural & 835 & $86.7 \%$ & 102 & $69.4 \%$ & 92 & $76.0 \%$ & 373 & $66.8 \%$ & 2019 & $70.2 \%$ & \\
\hline Age (mean) & 963 & 28.10 & 147 & 27.48 & 121 & 30.12 & 558 & 27.43 & 2876 & 27.79 & $<0.001$ \\
\hline \multicolumn{12}{|l|}{ Gender } \\
\hline Male & 463 & $48.1 \%$ & 90 & $61.2 \%$ & 75 & $62.0 \%$ & 313 & $56.1 \%$ & 1509 & $52.5 \%$ & \multirow[t]{2}{*}{0.001} \\
\hline Female & 500 & $51.9 \%$ & 57 & $38.8 \%$ & 46 & $38.0 \%$ & 245 & $43.9 \%$ & 1367 & $47.5 \%$ & \\
\hline \multicolumn{12}{|l|}{ Marital status } \\
\hline Single & 540 & $56.1 \%$ & 74 & $50.3 \%$ & 54 & $44.6 \%$ & 293 & $52.5 \%$ & 1412 & $49.1 \%$ & \multirow[t]{2}{*}{0.002} \\
\hline Married & 423 & $43.9 \%$ & 73 & $49.7 \%$ & 67 & $55.4 \%$ & 265 & $47.5 \%$ & 1464 & $50.9 \%$ & \\
\hline \multicolumn{12}{|l|}{ Education level } \\
\hline No education & 78 & $9.0 \%$ & 3 & $2.2 \%$ & 6 & $5.3 \%$ & 50 & $10.1 \%$ & 380 & $14.7 \%$ & \multirow[t]{4}{*}{$<0.001$} \\
\hline Primary & 631 & $73.1 \%$ & 79 & $57.7 \%$ & 86 & $76.1 \%$ & 273 & $55.4 \%$ & 1486 & $57.4 \%$ & \\
\hline Secondary & 114 & $13.2 \%$ & 42 & $30.7 \%$ & 17 & $15.0 \%$ & 121 & $24.5 \%$ & 556 & $21.5 \%$ & \\
\hline Higher & 40 & $4.6 \%$ & 13 & $9.5 \%$ & 4 & $3.5 \%$ & 49 & $9.9 \%$ & 168 & $6.5 \%$ & \\
\hline \multicolumn{12}{|l|}{ Occupation } \\
\hline Unemployed & 122 & $12.7 \%$ & 28 & $19.0 \%$ & 15 & $12.4 \%$ & 113 & $20.3 \%$ & 562 & $19.5 \%$ & \multirow[t]{3}{*}{$<0.001$} \\
\hline Farmer & 315 & $32.7 \%$ & 43 & $29.3 \%$ & 44 & $36.4 \%$ & 88 & $15.8 \%$ & 740 & $25.7 \%$ & \\
\hline Non-farmer & 526 & $54.6 \%$ & 76 & $51.7 \%$ & 62 & $51.2 \%$ & 357 & $64.0 \%$ & 1574 & $54.7 \%$ & \\
\hline \multicolumn{12}{|l|}{ Wealth status } \\
\hline Poorest & 455 & $51.6 \%$ & 25 & $23.1 \%$ & 14 & $16.1 \%$ & 137 & $34.0 \%$ & 814 & $34.0 \%$ & \multirow[t]{5}{*}{$<0.001$} \\
\hline Poorer & 173 & $19.6 \%$ & 30 & $27.8 \%$ & 24 & $27.6 \%$ & 34 & $8.4 \%$ & 280 & $11.7 \%$ & \\
\hline Middle & 142 & $16.1 \%$ & 28 & $25.9 \%$ & 25 & $28.7 \%$ & 69 & $17.1 \%$ & 349 & $14.6 \%$ & \\
\hline Richer & 72 & $8.2 \%$ & 16 & $14.8 \%$ & 17 & $19.5 \%$ & 67 & $16.6 \%$ & 402 & $16.8 \%$ & \\
\hline Richest & 39 & $4.4 \%$ & 9 & $8.3 \%$ & 7 & $8.0 \%$ & 96 & $23.8 \%$ & 548 & $22.9 \%$ & \\
\hline \multicolumn{12}{|l|}{ Health insurance } \\
\hline No & 96 & $10.0 \%$ & 12 & $8.2 \%$ & 9 & $7.4 \%$ & 33 & $5.9 \%$ & 102 & $3.5 \%$ & \multirow[t]{2}{*}{$<0.001$} \\
\hline Yes & 867 & $90.0 \%$ & 135 & $91.8 \%$ & 112 & $92.6 \%$ & 525 & $94.1 \%$ & 2774 & $96.5 \%$ & \\
\hline \multicolumn{12}{|c|}{ Transportation cost } \\
\hline$\leq$ Rp. 15,000,- & 619 & $64.3 \%$ & 111 & $75.5 \%$ & 84 & $69.4 \%$ & 451 & $80.8 \%$ & 1846 & $64.2 \%$ & $<0.001$ \\
\hline$>$ Rp. 15,000,- & 344 & $35.7 \%$ & 36 & $24.5 \%$ & 37 & $30.6 \%$ & 107 & $19.2 \%$ & 1030 & $35.8 \%$ & \\
\hline
\end{tabular}

night activities in farms, plantations, or forests [25, 2932]. The farmer patients in this study could have a history of malaria infection and treatment, which made them more likely to notice symptoms and seek for treatment earlier than non-farmers [33]. A previous study in Papua found that farmers left their homes after daybreak, between 4:00 a.m. until 5:00 p.m., which is still within the range of an active hour for Anopheles feeding habits and puts them at risk of transmission [34, 35]. Furthermore, findings in Aceh reported since many rice fields in Indonesia were located far from home, some farmers stayed in the rice fields for several days. Farmers 
Table 2 Logistic regression of anti-malarial treatment among malaria patients in Eastern Indonesia $(n=4665)$

\begin{tabular}{|c|c|c|}
\hline \multirow[t]{2}{*}{ Predictor } & \multicolumn{2}{|l|}{$\underline{\text { Malaria Treatment }}$} \\
\hline & adjusted OR (95\%Cl) & $p$-value \\
\hline \multicolumn{3}{|l|}{ Region/Province } \\
\hline East Nusa Tenggara & 1 (reference) & - \\
\hline Maluku & $0.258(0.161-0.413)$ & $<0.001$ \\
\hline North Maluku & $0.473(0.266-0.840)$ & 0.011 \\
\hline West Papua & $0.951(0.648-1.396)$ & 0.798 \\
\hline Papua & $0.894(0.682-1.172)$ & 0.418 \\
\hline \multicolumn{3}{|l|}{ Place of Residence } \\
\hline Urban & $0.545(0.431-0.689)$ & $<0.001$ \\
\hline Rural & 1 (reference) & - \\
\hline Age & 0.996 (0.988-1.003) & 0.242 \\
\hline \multicolumn{3}{|l|}{ Gender } \\
\hline Male & $0.978(0.796-1.201)$ & 0.831 \\
\hline Female & 1 (reference) & - \\
\hline \multicolumn{3}{|l|}{ Marital status } \\
\hline Single & 1 (reference) & - \\
\hline Married & $0.838(0.641-1.096)$ & 0.197 \\
\hline \multicolumn{3}{|l|}{ Education level } \\
\hline No education & 1 (reference) & - \\
\hline Primary & $0.785(0.552-1.116)$ & 0.178 \\
\hline Secondary & $0.973(0.624-1.408)$ & 0.755 \\
\hline Higher & $1.021(0.609-1.714)$ & 0.937 \\
\hline \multicolumn{3}{|l|}{ Occupation } \\
\hline Unemployed & 1 (reference) & - \\
\hline Farmer & $1.381(1.003-1.903)$ & 0.048 \\
\hline Non-farmer & $1.042(0.792-1.371)$ & 0.768 \\
\hline \multicolumn{3}{|l|}{ Wealth status } \\
\hline Poorest & 1 (reference) & - \\
\hline Poorer & $0.614(0.451-0.836)$ & 0.002 \\
\hline Middle & 1.033 (0.743-1.438) & 0.845 \\
\hline Richer & $0.630(0.463-0.857)$ & 0.003 \\
\hline Richest & $0.742(0.545-1.010)$ & 0.058 \\
\hline \multicolumn{3}{|l|}{ Health insurance } \\
\hline No & 1 (reference) & - \\
\hline Yes & $0.828(0.503-1.361)$ & 0.456 \\
\hline \multicolumn{3}{|l|}{ Transport cost } \\
\hline$\leq$ Rp. 15,000,- & $0.820(0.657-1.023)$ & 0.078 \\
\hline > Rp. 15,000,- & 1 (reference) & - \\
\hline
\end{tabular}

who were unable to return home every night stayed at forest suburban tree plantations for several nights to 2 weeks. Even more, they could spend up to 1 month in plantations located further in the forest, partially to work and partially to protect their crops from animals. During this period, farmers slept in simple huts [29].

Our present study found residence, occupation, and wealth status as significant predictors of anti-malarial drug treatment among malaria patients in the Eastern Indonesia. Similar studies also reported that malaria is generally prevalent in rural communities [36, 37], including several previous studies in Indonesia [25, 30, 38]. This condition could contribute to disparities between urban and rural areas in access to anti-malarial drug treatment among malaria patients [39, 40]. Additionally, it will get worse as the majority of Indonesians have difficulty getting proper healthcare [41]. Based on the 2018 Indonesia Basic Health Survey, knowledge of access to health facilities varied widely among residence types. Households in rural areas had difficulty in accessing hospitals (rural: $43 \%$ vs. urban: $13 \%$ ) and primary health centers (rural: $36.8 \%$ vs. urban $22.5 \%$ ) than households in urban [42].

Furthermore, the present study also revealed wealth status was associated with disparities in access to antimalarial drug treatment among malaria patients. Consistent with this finding, previous research explained the emphasis of interventions on the most disadvantaged groups was likely to be more effective in addressing disparities because of the association of malaria infection with low socioeconomic status [43]. It also explained the importance of approaching the problem solving through economic and social dimensions as well as epidemiological and geographic data as an analytical tool to help malaria control programs focus on vulnerable subpopulations [44]. Therefore, it is essential to strengthen the drug supply system to ensure the distribution and coverage of anti-malarial drug treatment. A previous study in rural Tanzania informed that information technology in reporting drug stocks (SMS for Life) was one type of the best practices in improving the efficiency and effectiveness of drug control. Besides that, regular counseling, exemption from medical expenses, and improved living environment also need to be provided [45].

Further analyses demonstrated that age, gender, marital status, education level, health insurance, and transportation cost were not associated with acquiring antimalarial drug treatment among malaria patients in the Eastern Indonesia. Although the researchers found education level was not the factor, intriguing evidence identified that anti-malarial drug treatment was more likely acquired by the respondents with primary education level. A previous study in Tanzania identified higher education levels were associated with a higher score of preventive practices. Meanwhile, the level of education was not in-line with seeking treatment behavior. Moreover, access to care and seeking for treatment were influenced by several other variables and culture [46]. 
Other findings also found that the transportation cost was not correlated with the outcome variable. However, transportation was a determinant factor associated with access to health care facilities. A study in Gambia revealed that free regular access to transportation significantly reduced delays in health care facility [47]. This result may be partly due to the improvement in malaria control program in general, particularly in the Eastern Indonesia [48]. Several previous studies have shown that easier accessibility could increase the effectiveness of anti-malarial drug treatment coverage $[41,49,50]$.

Another intriguing result in this study was that health insurance ownership was not associated to disparities in access anti-malarial drug treatment. The current research contradicts with a previous study that identified that proximity to health care facilities and access to health insurance were related to the use of care and treatment [51]. While it may not determine a single role, health insurance can minimize the disparity in access to health facilities between the rich and poor populations [52]. The converse results explained that multifactor levels i.e., individual, interpersonal, and institutional/structural levels influenced individual health behavior [53].

A previous study showed that one of the limitations of the Global Malaria Eradication Campaigns in the 1950s and 1960s was the belief that malaria eradication could be accomplished with a one-size-fits-all policy rather than adjusted strategies to local contexts [54]. According Oaks et al. [55], prevention strategies should include considerations relevant to community care-seeking behaviors to gain successful adoption of malaria control methods in endemic areas. For example, preference for a traditional birth attendant has resulted in collaboration between village midwives and birth attendants in some areas of Indonesia [56], including in ENT where 'Sembur' culture serves as a local wisdom in care of pregnant mother with malaria in Kupang [57]. This approach integrated traditional healers with health promotion and thus led to better involvement with formal health treatment. Therefore, a local wisdom approach like this may be more successful in addressing disparities in accessing anti-malarial drug treatment in Eastern Indonesia. Other example of local wisdom approach is indigenous leaders were engaged as village health volunteers (VHVs). VHVs have been highlighted as an important primary healthcare provider in rural PNG, where they have diagnosed and treated acute malaria cases. VHVs are the most accessible health-care staff to residents, thus could be a cost-effective and practical strategy to expand antimalarial access [58]. Local wisdom is wisdom passed down from generation to generation or seen as experience of some groups in organizing social life and adjusting it to the environment to meet social needs, especially in attitude and actions [59]. Interventions in health promotion that use respectful and relevant local wisdom methods may improve the penetration and durability of positive behavioral change. Best-practice health promotion can be accomplished by integrating local wisdom at any health promotion levels through the empowerment of local societies, their traditions, and certain environmental conditions [60].

Our study has certain limitations. First, this study is cross-sectional, so that we could not infer the causal relationships, the gaps found and revealed in this study are still limited to a depthless understanding. Second, we should note that malaria cases of this study were selfreported malaria. There were no diagnostic tests to confirm malaria infection among participants. Third, children were not included in this study, regardless of the fact that malaria is a major concern not only for adults but also for children under the age of five. Therefore, we should cautiously interpret the results as this could lead to biases (e.g., reporting bias and social desirability bias).

\section{Conclusions}

The study concludes there were sub-national disparities in accessing anti-malarial drug treatment in Eastern Indonesia. Moreover, the study also found that regions, places of residence, occupation, and wealth status were predictors in accessing anti-malarial drug treatment. Findings from this study could be used as baseline information to improve access to anti-malarial drug treatment and better target malaria intervention in Eastern Indonesia.

\section{Acknowledgments \\ The author would like to thank the National Institute of Health Research and Development of the Indonesia Ministry of Health for providing access to the} 2018 Indonesia Basic Health Survey data analyzed in this study.

Authors' contributions

$\mathrm{MI}$ and $\mathrm{ADL}$ developed the proposal, analyzed, interpreted the data, and led the manuscript writing. EPA, HP, FYP, JH, AR, HS, and IRFE contributed in interpreting the data and writing the manuscript. All authors read and approved the final manuscript.

\section{Funding}

Not applicable.

\section{Availability of data and materials}

The data that support the findings of this study are available from the Data Management Laboratory of the National Institute of Health Research and Development (NIHRD), the Ministry of Health of the Republic of Indonesia under license and so cannot be made freely available. Data can be made available after approval of a written request to the Data Management Laboratory-NIHRD (via mandat@litbang.depkes.go.id/labmandat. litbangkes@gmail.com).

\section{Declarations}

Ethics approval and consent to participate

The ministry of health conducts the 2018 Indonesia Basic Health Survey following the Helsinki Declaration. The National Ethics Commission approved it for Health Research, National Institute of Health Research and Development (NIHRD), the Ministry of Health of the Republic of Indonesia (ethic number: LB.02.01/2/KE.024/2018). The study deleted all respondents' 
identities from the dataset. Respondents have provided written approval for their involvement in the research. Before the interview, the interviewer gave consent forms to all members of the family. The survey interviewed parents or guardians (household heads, their spouses, or an older representative of the house) and all household members who consented.

\section{Consent for publication}

Not applicable.

\section{Competing interests}

The authors declare that they have no competing interests.

\section{Author details}

${ }^{1}$ Pangandaran Unit for Health Research and Development, National Institute of Health Research and Development, Ministry of Health of Indonesia, Pangandaran, West Java, Indonesia. ${ }^{2}$ National, Ministry of Health of Indonesia, National Institute of Health Research and Development, Jakarta, Indonesia. ${ }^{3}$ Eijkman-Oxford Clinical Research Unit, Jakarta, Indonesia. ${ }^{4}$ Centre for Tropical Medicine, Faculty of Medicine, Public Health and Nursing, Universitas Gadjah Mada, Yogyakarta, Indonesia.

\section{Received: 15 December 2020 Accepted: 4 August 2021}

\section{Published online: 13 August 2021}

\section{References}

1. World Health Organization. (2015). Guidelines for the treatment of malaria, 3rd ed. World Health Organization. https://apps.who.int/iris/handle/10665/ 162441

2. World Health Organizaton (WHO). World Malaria Report 2020, vol. 2020. Geneva: World Health Organization; 2020. https://www.who.int/

3. Pava Z, Burdam FH, Handayuni I, Trianty L, Utami RAS, Tirta YK, et al. Submicroscopic and asymptomatic plasmodium parasitaemia associated with significant risk of anaemia in Papua, Indonesia. PLoS One. 2016;11(10): e0165340. https://doi.org/10.1371/journal.pone.0165340.

4. World Health Organization Malaria Team. World Malaria Report 2019. 2019.

5. National Institute of Health Research and Development of The Indonesia Ministry of Health. The 2018 Indonesia Basic Health Survey (Riskesdas). Jakarta: National Report; 2019. [thesis].p

6. Hanandita W, Tampubolon G. Geography and social distribution of malaria in Indonesian Papua: a cross-sectional study. Int J Health Geogr. 2016;15(1): 13. https://doi.org/10.1186/s12942-016-0043-y.

7. Ministry of Health Republic of Indonesia. Decree Number 293/Menkes/SK IV/2009 concerning malaria elimination in Indonesia Ministry of Health Republic of Indonesia ed. 2009

8. Ministry of Health Republic of Indonesia. Implementation of Early Detection and Administration of Anti-Malaria Drugs by Malaria Cadres in Areas with Special Situations. 2018

9. Ministry of Health Republic of Indonesia. Jakarta: Indonesia Health Profile; 2019. https://pusdatin.kemkes.go.id/folder/view/01/structure-publikasi-datapusat-data-dan-informasi.html.

10. World Health Organization. WHO informal consultation on fever management in peripheral health care settings: a global review of evidence and practice. World Health Organization. 2013. https://apps.who.int/iris/ha ndle/10665/95116.

11. Xu J-W, Xu Q-Z, ZY-R LH. Malaria treatment-seeking behavior and related factors of Wa ethnic minority in Myanmar: a cross-sectional study. Malar J. 2012;11:417.

12. Romay-Barja M, Cano J, Ncogo P, Nseng G, Santana-Morales MA, Valladares $B$, et al. Determinants of delay in malaria care-seeking behaviour for children 15 years and under in Bata district, Equatorial Guinea. Malar J. 2016; 15:187.

13. Laar A, Laar AKDP. Community perception of malaria and its influence on health-seeking behaviour in rural Ghana: a descriptive study. Malar World J. 2013:4:1-4.

14. Lawal AM, Balogun SKBB. Knowledge of transmission, malaria belief and health-seeking behaviour in Oye-Ekiti local government area of Ekiti state, Nigeria. Am J Rural Dev. 2014;2:8-12.

15. Karyana M, Devine A, Kenangalem E, Burdarm L, VR PJR, et al. Treatmentseeking behaviour and associated costs for malaria in Papua, Indonesia. Malar J. 2016;15:536.
16. Chuma J, Okungu V, Molyneux C. Barriers to prompt and effective malaria treatment among the poorest population in Kenya. Malar J. 2010;9:144. https://doi.org/10.1186/1475-2875-9-144. PMID: 20507555; PMCID: PMC2892503.

17. Kizito J, Kayendeke M, Nabirye C, Staedke SGCC. Improving access to health care for malaria in Africa: a review of literature on what attracts patients. Malar J. 2012;11(1):55. https://doi.org/10.1186/1475-2875-11-55.

18. Iwelunmor J, Idris O, Adelakun AAC. Child malaria treatment decisions by mothers of children less than five years of age attending an outpatient clinic in south-West Nigeria: an application of the PEN-3 cultural model. Malar J. 2010;9(1):354. https://doi.org/10.1186/1475-2875-9-354.

19. Provincal Bureau of Statistics of Maluku. Maluku province in figure. Ambon: Provincal Bureau of Statistics of Maluku. 2018.

20. Provincal Bureau of Statistics of North Maluku. North Maluku in figure. North Maluku: Provincal Bureau of Statistics of North Maluku. 2019.[thesis].p.

21. Provincal Bureau of Statistics of East Nusa Tenggara. East Nusa Tenggara province in figure. Kupang: Provincal Bureau of Statistics of East Nusa Tenggara; 2019.

22. Provincal Bureau of Statistics of West Papua. West Papua province in figure. West Papua: Provincal Bureau of Statistics of West Papua; 2018.[thesis].p

23. Provincal Bureau of Statistics of Papua. Papua province in figure. Jayapura: Provincal Bureau of Statistics of Papua; 2018. [thesis].p

24. Ministry of Health. Strategic Plan of The Ministry of Health Republic of Indonesia 2015-2019. Jakarta. 2015.

25. Ipa M, Widawati M, Laksono ADK, I DP. Variation of preventive practices and its association with malaria infection in eastern Indonesia: Findings from communitybased survey. PLoS One. 2020;15(5):e02.

26. Berendes S, Heywood P, Oliver SGP. Quality of private and public ambulatory health care in low and middle income countries: systematic review of comparative studies. PloS Med. 2011;8:e100043. https://doi.org/1 0.1371/journal.pmed.1000433 PMID: 21532746.

27. Rao BV, Schellenberg DGA. Overcoming health systems barriers to successful malaria treatment. Trends Parasitol. 2013;29:164. https://doi.org/1 0.1016/j.pt.2013.01.005 PMID: 23415933.

28. Rao BV, Schellenberg DGA. The potential impact of improving appropriate treatment for fever on malaria and non-malaria febrile illness management in under-5s: a decision-tree modeling approach. PLoS One. 2013;8:e69654. https://doi.org/10.1371/journal.pone.0069654 PMID: 23922770.

29. Ekawati $\mathrm{KCJ}$ LL, Jacobson JO, Cueto CA, Zarlinda I, IRF E, Fatah A, et al. Defining malaria risks among forest workers in Aceh, Indonesia: a formative assessment. Malar J. 2020;19:441. https://doi.org/10.1186/s12936-020-03 $511-2$.

30. Dhewantara PW, Ipa M, Widawati M. Individual and contextual factors predicting self-reported malaria among adults in eastern Indonesia: findings from Indonesian community-based survey. Malar J. 2019;18:1-17.

31. SULISTYAWATI S, FITRIANI I. Risk Factor and Cluster Analysis to Identify Malaria Hot Spot for Control Strategy in Samigaluh Sub-District, Kulon Progo, Indonesia. Iran J Public Health. 48(9):1647-53.

32. Ministry of Health Indonesia. Malaria Data and Information: Jakarta Minist Heal Indones; 2016.

33. Mekonnen BW, FA. Early treatment-seeking behaviour for malaria in febrile patients in northwest Ethiopia. Malar J. 2018;17:406. https://doi.org/10.1186/ s12936-018-2556-2.

34. Ototo EN, Mbugi JP, Wanjala CL, Zhou G, Githeko AK, Yan G. Surveillance of malaria vector population density and biting behaviour in western Kenya. Malar J. 2015;14(1):244. https://doi.org/10.1186/s12936-015-0763-7.

35. St Laurent B, Supratman S, Asih PB, Bretz D, Mueller J, Miller HC, Baharuddin A, Shinta, Surya A, Ngai M, Laihad F, Syafruddin D, Hawley WA, Collins FH, Lobo NF. Behaviour and molecular identification of Anopheles malaria vectors in Jayapura district, Papua province, Indonesia. Malar J. 2016;15:192. 10.1186/s12936-016-1234-5. PMID: 27060058; PMCID: PMC4826537.

36. Tefera DR, Sinkie SO, Daka DW. Economic burden of malaria and associated factors among rural households in Chewaka District, Western Ethiopia. Clin Econ Outcomes Res. 2020;12:141-52.

37. Hay SI, Guerra CA, Tatem AJ, Atkinson PM, Snow RW. Urbanization, malaria transmission and disease burden in Africa. Nat Rev Microbiol. 2005;3(1):8190. https://doi.org/10.1038/nrmicro1069.

38. Hasyim H, Dale P, Groneberg DA. et al. Social determinants of malaria in an endemic area of Indonesia. Malar J. 2019;18:134. https://doi.org/10.1186/s12 936-019-2760-8 
39. Khatib RA, Selemani M, Mrisho GA, et al. Access to artemisinin-based antimalarial treatment and its related factors in rural Tanzania. Malar J. 2013; 12(1):155.

40. Smith N, Obala A, Simiyu C, Diana Menya BK-O, O'Meara WP. Accessibility, availability and affordability of anti-malarials in a rural district in Kenya after implementation of a national subsidy scheme. Malar J. 2010;10:316.

41. Elyazar IRF, , Simon I. Hay and JKB. Malaria distribution, prevalence, drug resistance and control in Indonesia. Adv Parasitol 2011; 74: 41-175.doi: https://doi.org/10.1016/B978-0-12-385897-9.00002-1.

42. National Institute of Health Research and Development Indonesia. Indonesian Basic Health Survey. Jakarta; 2018.

43. Tusting LS, Willey B, Lucas H, Thompson J, Kafy HT, Smith RLS Socioeconomic development as an intervention against malaria: a systematic review and meta-analysis. Lancet. 2013;382(9896):963-72. https:// doi.org/10.1016/S0140-6736(13)60851-X.

44. Steele JE, Sundsoy PR, Pezzulo C, Alegana VA, Bird TJ, Blumenstock J, et al. Mapping poverty using mobile phone and satellite data. J R Soc Interface. 2017;14:12.

45. Barrington J, Wereko-Brobby O, Ward PMWK. SMS for Life: a pilot project to improve anti-malarial drug supply management in rural Tanzania using standard technology. Malar J. 2010;9(298):1-9.

46. Spjeldnæs AO, Kitua AY, Blomberg B. Education and knowledge helps combating malaria, but not degedege: a cross-sectional study in Rufiji, Tanzania. Malar J. 2014;13:200.

47. Rees CP, Hawkesworth SMS, Dondeh BLUS. Factors affecting access to healthcare: an observational study of children under 5 years of age presenting to a rural gambian primary healthcare centre. PLoS One. 2016; 11(6):e01. https://doi.org/10.1371/journal.pone.0157790.

48. Sitohang V, Sariwati E, Fajariyani SB, Hwang D, Kurnia B, RKHFJ L, et al. Malaria elimination in Indonesia: halfway there. [Published Online April 24]. Lancet Glob Heal. 2018;6(18):30198-0. https://doi.org/10.1016/ S2214-109X.

49. Ameh S, Welaga P, Kabiru WC, Ndifon W, et al. Factors associated with appropriate home management of uncomplicated malaria in children in Kassena-Nankana district of Ghana and implications for community case management of childhood illness: a cross-sectional study. BMC Public Health. 2015;15:458.

50. Kebede Y, Abebe LAG, Sudhakar MBZ. School-based social and behavior change communication (SBCC) advances community exposure to malaria messages, acceptance, and preventive practices in Ethiopia: a pre-posttest study. PLoS One. 2020;15(6):e02.

51. Robyn PJ, Fink G, Sié ASR. Health insurance and health-seeking behavior: evidence from a randomized community-based insurance rollout in rural Burkina Faso. Soc Sci Med. 2012;75(4):595-603. https://doi.org/10.1016/j. socscimed.2011.12.018.

52. Johar M, Soewondo P, Pujisubekti R, Satrio HK, Adji A. Inequality in access to health care, health insurance and the role of supply factors. Soc Sci Med. 2018;213:134-45. https://doi.org/10.1016/j.socscimed.2018.07.044.

53. Kumar S, Quinn SC, Kim KH, Musa D, Hilyard KMFV. The social ecological model as a framework for determinants of $2009 \mathrm{H} 1 \mathrm{~N} 1$ influ- enza vaccine uptake in the US. Heal Educ Behav. 2012;39(2):229-43. https://doi.org/10.11 77/1090198111415105.

54. Atkinson J, Valley A, Fitzgerald L, Whittaker M, Riley ITM. The architecture and effect of participation: a systematic review of communicable disease control and elimination. Implication for malaria elimination. Malar J. 2011:10:225.

55. Oaks SC Jr, Mitchell VS, Pearson GWCC. Social and behavioral aspects of malaria. In: Malaria: Obstacles and Opportunities. Washington DC: The National Academies of Sciences, Engineering, and Medicine National Academy Press; 1991.

56. Nasir S, Ahmed R, Kurniasari M, Limato R, Tulloch O, K de K DS. Challenges that hinder Parturients to deliver in health facilities: a qualitative analysis in two districts of Indonesia. Makara J Heal Res. 2016;20(3):79-87.

57. Kapitan M, AJAFK YD. 'Sembur' culture: Local wisdom in care of pregnant mother with malaria in kupang. ETNOSIA J Etnogr Indones. 2021;5(1):150.

58. Yoshii A, Sekihara M, Furusawa T, Hombhanje F, Tsukahara T. Factors associated with children's health facility visits for primaquine treatment in rural Papua New Guinea. Malar J. 2019;18(1):42. https://doi.org/10.1186/s12 936-019-2675-4

59. Purba AR, Herlina JS. Meaning and Function of Local Wisdom in the Proverb (Limbaga) Simalungun. Budapest Int Res Critics Institute-J. 2020;3(4): 3904-11.
60. Demaio A. Local wisdom and health promotion: barrier or catalyst? Asia Pacific J Public Heal. 2009;23:127-32.

\section{Publisher's Note}

Springer Nature remains neutral with regard to jurisdictional claims in published maps and institutional affiliations.
Ready to submit your research? Choose BMC and benefit from:

- fast, convenient online submission

- thorough peer review by experienced researchers in your field

- rapid publication on acceptance

- support for research data, including large and complex data types

- gold Open Access which fosters wider collaboration and increased citations

- maximum visibility for your research: over $100 \mathrm{M}$ website views per year

At BMC, research is always in progress.

Learn more biomedcentral.com/submissions 